\title{
Study the effect of honey ingestion on recognition of Aspergillus fumigatus by peritoneal macrophages
}

\section{Donya Nikaein ${ }^{1,2^{*}}$, Alireza Khosravi ${ }^{1,2}$, Aghil Sharifzadeh ${ }^{1,2}$}

1. Mycology Research Center, Faculty of Veterinary Medicine, University of Tehran, Tehran, Iran

2. Department of Microbiology and Immunology, Faculty of Veterinary Medicine, University of Tehran, Tehran, Iran

Email: dnikaein@ut.ac.ir

Introduction: Invasive aspergillosis (IA) is one of the most severe systemic fungal diseases caused by the opportunistic fungus Aspergillus. It is the main reason of fungal related mortality in high risk patients. The most important predisposing factor known is quantitative and/or qualitative defect in neutrophils; however the increase in the number of IA in nonneutropenic immunocompromised patients highlights the importance of non-neutrophil defense-related factors.These mechanisms may include the recognition of the microorganism, recruitment of leucocytes other than neutrophils and effector mechanisms of recruited or resident cells. In this study we examined the effect of three Iranian honeys including Thyme, Pennyroyal and Astragalus Honeys on TLR2 and TLR4 gene expressions in mice involving with Invasive Aspergillosis.

Materials and Methods: BALB/c mice weighing between $\mathbf{2 0}-\mathbf{3 0} \mathrm{gr}$ were divided into 10 groups (honey alone, honey and infection, negative and positive controls) each containing 10 . Mice were treated with honey (1.5 g/kg BW/orally) for 10 days. At day 6 , mice in infection group were infected with Aspergillus fumigatus conidia $(5 \times 105 / \mathrm{ml})$ intravenously. Animals were sacrificed at day 11 and their peritoneal macrophages were cultured. The mRNA from macrophages was extracted and TLR2 and TLR4 gene expression was determined by semi-quantitative RTPCR.

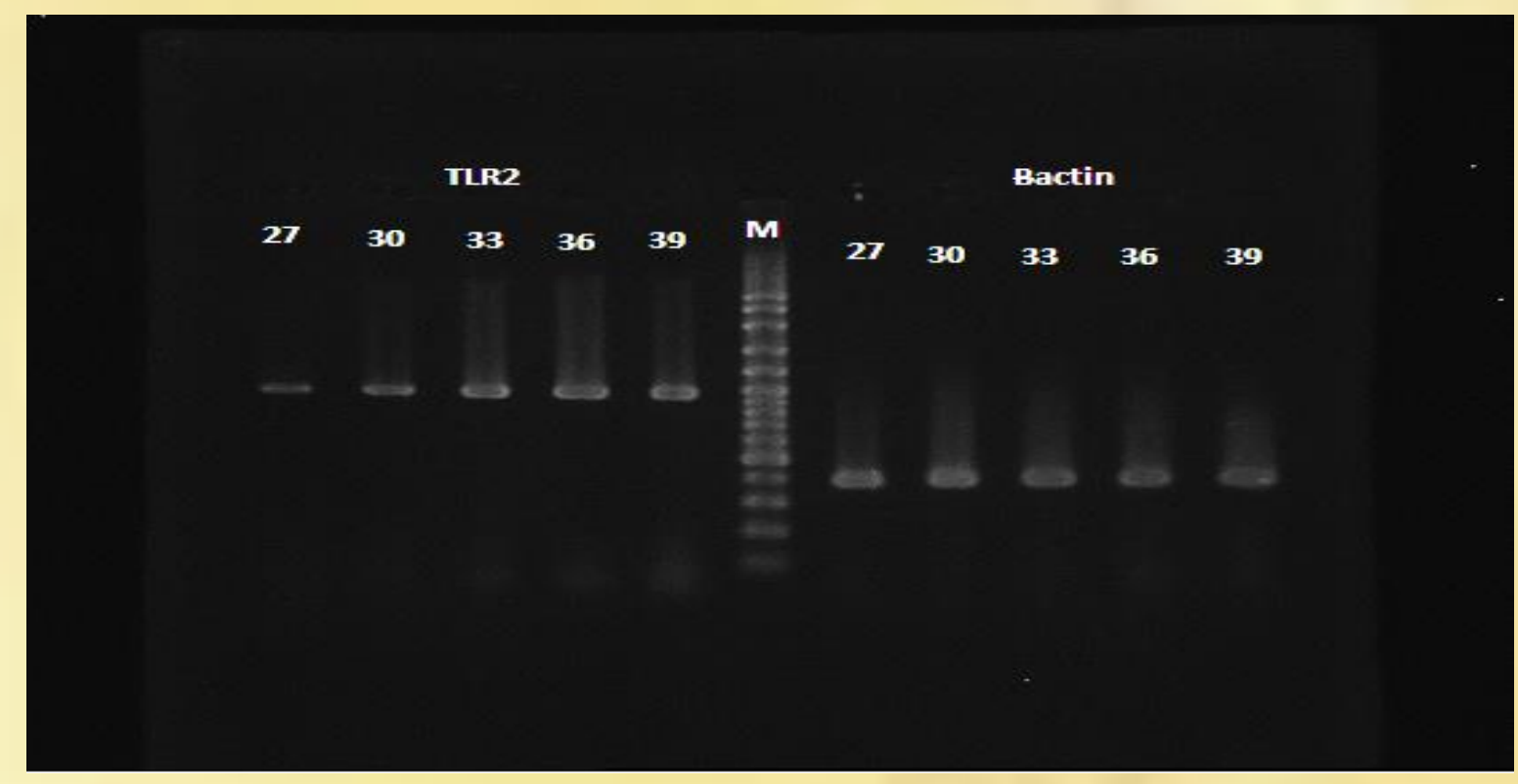

Figure 1- Evaluation of suitable RT-PCR cycles
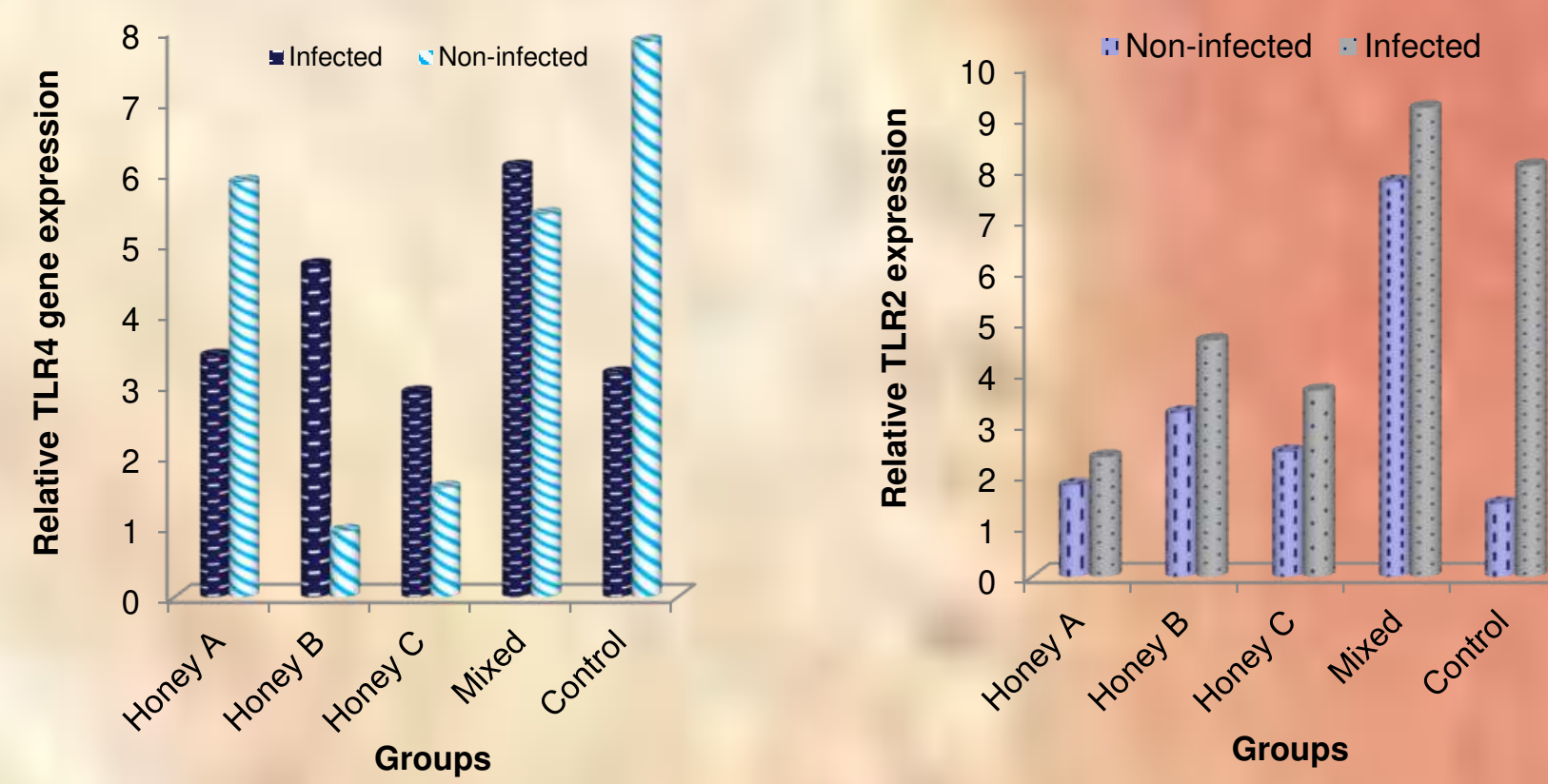

Figure 2- Relative TLR2 \&TLR4 gene expression in different groups

Results: The results showed that TLR2 expression by peritoneal macrophages had decreased in all honey treated mice in comparison to control group, however this decrease was not significant except in mice receiving Thyme honey $(p>0.05)$. Among infection groups, only infected mice treated with Pennyroyal had significantly higher TLR2 expression; while TLR2 expression had increase in all honey treated groups comparing to normal saline treated mice. TLR4 expression showed that infected groups had higher TLR4 expression comparing to non-infected groups and this increase was significant among mice treated with Pennyroyal and Astragalus honeys $(p<0.05)$. All honey treated infected groups had lower TLR4 expression than saline treated infection group $(p<0.05)$.

Conclusion: It can be concluded that honey could increase Aspergillus recognition by peritoneal macrophages, however in order to illuminate the exact mechanism of action of honey on innate immune responses during invasive aspergillosis, more studies are necessary in the future.

References:

Park, S.J. and B. Mehrad, Innate immunity to Aspergillus species. Clinical microbiology reviews, 2009. 22(4): p. 535-551.

2. Meier, A., Kirschning, C. J., Nikolaus, T., Wagner, H., Heesemann, J., \& Ebel, F. (2003). Toll-like receptor (TLR) 2 and TLR4 are essential for Aspergillus-induced activation of murine macrophages. Cellular microbiology, 5(8), 561-570.

3. Braedel, S., Radsak, M., Einsele, H., Latgé, J. P., Michan, A., Loeffler, J., ... \& Hebart, H. (2004). Aspergillus fumigatus antigens activate innate immune cells via toll-like receptors 2 and 4. British journal of haematology, 125(3), 392-399.

4. Roeder, A., Kirschning, C. J., Rupec, R. A., Schaller, M., Weindl, G., \& Korting, H. C. (2004). Toll-like receptors as key mediators in innate antifungal immunity. Medical Mycology, 42(6), 485-498.

5. Liu, C., Wang, M., Sun, W., Cai, F., Geng, S., Su, X., \& Shi, Y. (2017). PU. 1 serves a critical role in the innate defense against Aspergillus fumigatus via dendritic cellassociated C-type lectin receptor-1 and toll-like receptors-2 and 4 in THP-1-derived macrophages. Molecular medicine reports, 15(6), 4084-4092. 